\title{
Impact of COVID-19 News on Performance of Indonesia Stock Market
}

\author{
A. Mulyo Haryanto ${ }^{1,2, *}$, Wisnu Mawardi ${ }^{2}$ \\ ${ }^{1}$ Faculty of Economics and Business, Diponegoro University, Indonesia \\ ${ }^{2}$ Department of Management, Diponegoro University, Indonesia
}

Received February 2, 2021; Revised March 17, 2021; Accepted April 18, 2021

\section{Cite This Paper in the following Citation Styles}

(a): [1] A. Mulyo Haryanto, Wisnu Mawardi , "Impact of COVID-19 News on Performance of Indonesia Stock Market," Universal Journal of Accounting and Finance, Vol. 9, No. 2, pp. 226 - 231 , 2021. DOI: 10.13189/ujaf.2021.090212.

(b): A. Mulyo Haryanto, Wisnu Mawardi (2021). Impact of COVID-19 News on Performance of Indonesia Stock Market. Universal Journal of Accounting and Finance, 9(2), 226 - 231. DOI: 10.13189/ujaf.2021.090212.

Copyright $@ 2021$ by authors, all rights reserved. Authors agree that this article remains permanently open access under the terms of the Creative Commons Attribution License 4.0 International License

\begin{abstract}
This research tries to show that information about COVID-19 affects market arousal indicated by the frequency of transactions, and the market performance shown by Jakarta Composite Index (JCI). The theory used for analysis is the prospect theory and efficient market hypothesis (EMH). The results of statistical analysis indicate that information about COVID has a negative effect on JCI, as well as trading volume the previous day. The evidence can briefly prove that there is an effect of COVID-19 and weakening daily transactions on JCI. The research findings show that the JCI market uncertainty is in line with the VUCA and Prospect theory. In this case, it occurs that uncertainty affects the behavior of investors' decision making. Investors' decision-making behavior is accumulated in market behavior, and is subsequently manifested in index changes in accordance with the efficient market hypothesis. The contribution of this research to the study of financial market behavior is that uncertainty and uncertainty faced by investors affect market behavior and changes as measured by the index.
\end{abstract}

Keywords COVID-19, Prospect Theory, Rumors, Market Sentiment and Stock Market Performance

\section{Introduction}

Uncertainty that occurred on the Indonesian stock exchange (IDX) as well as various world exchanges caused by Covid-19 can be matched with VUCA (velocity, uncertainty, complexity, and ambiguity). It is stated in the VUCA concept that the current business environment (from 1990 - 2014) is full of difficult-to-predict of VUCA condition [1]. All take place quickly, full of uncertainness, very complicated relationships with each other and also create confusion and hesitation. VUCA'S condition also occurred at the time of the Covid-19 outbreak. The response to the uncertain, and stressful situation can also be traced and attributed to prospect theory [2]. There was a decrease in Jakarta Composite Index (JCI) in the early period of 2020 in line with the outbreak of Covid-19.

The conditions reflected in VUCA and prospect theory can be attributed to the current Covid-19 outbreak. At this time where the Covid-19 outbreak is still ongoing it is known that business activities and financial markets (foreign exchange rates) and capital markets are fluctuated, and business prospects are also experiencing as due to lock downs in many countries. The complexity of the situation also occurs because the transportation, oil, and manufacture industries are also hit, all hooks attached to each other. State leaders as well as businesses are also experiencing confusion and hesitation in making decisions due to all-round suddenness and limited data. More news, and discussion, news disbanding data and analysis. It all happened because it happened surprisingly and quickly. Talk of news topics, discussion of something that is widely circulated [3]. News as one of the sources of discussion or discussion and provoke responses that have been widely circulated and discussed widely is also known to have an impact on perception, and concern in the community as well as business people. In addition to news and extensive 
talks on Covid-19, it is also known that various policies on the partial lockdown in Indonesia add to the economic burden in the form of a partial closure of business activities that are sure to have a direct impact on the economy, through the transportation, distribution, production and trade sectors and services.

Based on that rumors affect predictions and expectations through the mechanism of behave. In accordance with the context of Schindler's [3] actions, the news and extensive discussion of important topics (in this case, Covid-19 rumors) can affect the perception, expectations of investors in making investment decisions in financial markets. In other words, the news can affect market sentiment. Finally, it can be concluded that this study seeks to explain how Covid-19 news impacts investment transaction decisions on the market or market sentiment, and further how that market sentiment affects market performance. Empirically research of the impact of Covid-19 news on market performance is useful to examine how information of Covid-19 news impacts market performance, in this case IDX. Indirectly this research also explores the implementation of two aspects of agency theory namely: about the risk and the absence of asymmetry information will cause a difference in the expected return rate.

\section{Theoretical Review}

\subsection{Efficient Market Hypothesis}

In the agency theory highlighted three things: the absence of conflicts of interest related to ownership, about risk preferences, and information asymmetry [4]. Some investors or traders in the capital market are people who are co-opting or noise traders. They lack or do not understand the information so that the action comes along (herding). However, because of the large number, bias affects the market [5]. The Efficient Market Hypothesis theory states that all information about the company is reflected in the share price, thus the change in the share price reflects the change in the value of the company as measured by the performance it achieves. The relationship between the company's performance and the market can be seen from the assumptions raised. First that market participants are rational. In fact, the rationality of the investor is different (random) depending on the information he receives [6]. In terms of traders, they can be grouped into well informed traders and participating traders. Secondly, investors take advantage of the development of market information in the form of price movements associated with fundamental analysis and technical analysis. As such EMH is close to CAPM analysis which is a risk analysis based on changes in individual stock prices and market changes. The reason why EMH is largely ignored, because of EMH's failure to predict and explain asset bubble, excessive market reaction, excessive stock price volatility [5]. Based on this, the theory of market risk and market behavior is reasonable. However, EMH continues to contribute that decisions about pricing and investment are influenced by information that is later reflected in pricing. In other words, the share price is an assessment or reflection of investor expectations, which is the result of the various information it receives. In $\mathrm{EMH}$ it can also be explained that the investor there is a really understanding and there is origin (noise trader), and this is the source of the market sentiment as well. This market sentiment can be identified from the market passion reflected by the number of transactions in the capital market.

\subsection{Prospect Theory}

The application of Prospect Theory does in-aggregate stock market return puzzles was reviewed by Bing Han and Hsu [7], which stated that prospect theory can explain how the complexity of aggregate stock market mechanisms is reviewed. It is assumed in this theory that the behavior of risk aversion by investors depends on his previous experience. If they have experience that the results in the capital markets are good enough, they will go back after shock, because the losses in the past will soon be recoverable by future earnings. However, if they lose enough then they will be less averse or less daring to take risks. Prospect theory also underscores the in-line risk premium that investors want higher incomes if there are frequent fluctuations, so they hope that once there is a loss then a bigger and faster recovery is demanded by them. In short investors will see various movements of risk and income opportunities in the capital market [7, 8]. This theory suggests that investors will continue to make investments and make investment decisions based on opportunities on the conditions that will date. Any shocks or stocks will soon be followed by recovery as long as there is still a good chance in the dating period.

\section{Method}

The research model initiated is that JCI is influenced by information about Covid-19. The Covid-19 information will likely affect the behavior of traders and brokers [9]. Similarly, there has been evidence that there is an influence of Covid-19 death toll on the stock market performance of various European countries [10]. In addition to researching the impact of Covid-19 models compiled can be based on the theory of efficient market hypothesis (EMH) which states that all information will be reflected in the market price, and that market price is also a reflection of investor expectations. Changes in market prices will ultimately impact stock indices. In addition, based on the theory prospects that the behavior of investors who risk aversion 
will move their investment to sectors that are considered safe. If there is an impact of Covid-19 on the company's performance, the investor will sell his shares and transfer to other forms of investment. Data that can be proxied for the condition or performance of the stock market is the frequency of trading. Meanwhile, the use of real time models (at the time) and lag t- 1 and $t-2$ over Covid- 19 news was carried out in previous investigation [11], while some have examined the impact of the Covid-19 outbreak on economic activities [12].

The basis of the theory and also previous research, where Covid-19 news can have an effect in real time, da also lag-time. In addition, based on research and experience that investment decisions and stock transactions are influenced by previous performance and conditions, the following econometry equation models can be prepared.

$$
\begin{gathered}
\mathrm{JCI}=\mathrm{f}(\text { Covid-19 } \text { daily information, previous market } \\
\text { performance })
\end{gathered}
$$

$$
\mathrm{JCI}=\alpha+\beta(\text { Case })+\text { Trade Frequency (t-1) }
$$

In this study, Covid-19 information is projected with the number of cases per day in the period of daily data. Trade Frequency Lag is defined as Frequency of Total trade lag (daily data).

The observation period of this study is from March 2, 2020 to June 12, 2020. It could be considered quite safe and representative according to the daily data from the official announcement, until the end of the observation period is $n$ $=67$ working days of the IDX stock exchange (holidays are not taken into account). Daily stock performance is OJK (daily transaction); for Covid-19 data the source is from Wikipedia webpage on Covid-19 pandemic in Indonesia (http://en.m.wikipedia.org/wiki/Covid-19_pandemic_in_I ndonesia).

\section{Results}

The results showed the descriptive statistics and correlations of variables used in this study (Table 1; Table 2).
Table 1. Descriptive Statistics

\begin{tabular}{|c|c|c|c|}
\hline & Mean & Std. Deviation & $\mathrm{N}$ \\
\hline Composite & 4258.78 & 1422.993 & 74 \\
\hline Covid-19 case & 386.47 & 311.378 & 74 \\
\hline LagTot.Freq & 510464.6892 & 215850.02900 & 74 \\
\hline
\end{tabular}

Table 2. Pearson Correlations

\begin{tabular}{|c|c|c|c|c|}
\hline \multicolumn{2}{|c|}{} & Composite & $\begin{array}{c}\text { Covid-19 } \\
\text { case }\end{array}$ & LagTot.Freq \\
\hline \multirow{3}{*}{$\begin{array}{c}\text { Pearson } \\
\text { Correlation }\end{array}$} & Composite & 1.000 & -.126 & .776 \\
\cline { 2 - 5 } & Covid-19 case & -.126 & 1.000 & .252 \\
\cline { 2 - 5 } & LagTot.Freq & .776 & .252 & 1.000 \\
\hline \multirow{4}{*}{ Sig. (1-tailed) } & Composite &. & .142 & .000 \\
\cline { 2 - 5 } & Covid-19 case & .142 &. & .015 \\
\cline { 2 - 5 } & LagTot.Freq & .000 & .015 &. \\
\hline \multirow{3}{*}{$\mathrm{N}$} & Composite & 74 & 74 & 74 \\
\cline { 2 - 5 } & Covid-19 case & 74 & 74 & 74 \\
\cline { 2 - 5 } & LagTot.Freq & 74 & 74 & 74 \\
\hline
\end{tabular}

Moreover, data processing with SPSS version 22 generates the value of Adjusted R-square is $73.10 \%$. A high Adjusted R-square revealed in this study indicates that market conditions reflected by the volatility of transaction activity, as well as the news about Covid-19 being able to become a high estimator/predictor. This indicates that however the Covid-19 outbreak is able to affect the performance of the capital market [12].

Table 3. Adjusted R-square

\begin{tabular}{|c|c|c|c|}
\hline Model & R & R Square & Adjusted R Square \\
\hline 1 & $.855^{\mathrm{a}}$ & .731 & .715 \\
\hline
\end{tabular}

The findings as shown in Table 3 showed that the influence possibly depends on the length of the partial lockdown which affects economic activity and will further provide a negative signal for investors. The condition of declining activity and the potential for losses that will be dating is a driver of negative expectations with the result of further decline in market activity and increasing negative market sentiment, this negative market sentiment is ultimately also depressing JCI.

Table 4. ANOVA

\begin{tabular}{|c|c|c|c|c|c|c|}
\hline \multicolumn{2}{|c|}{ Model } & Sum of Squares & Df & Mean Square & F & Sig. \\
\hline \multirow{3}{*}{1} & Regression & 105329598.100 & 2 & 52664799.050 & 88.004 & $.000^{\mathrm{b}}$ \\
\cline { 2 - 7 } & Residual & 42488824.058 & 71 & 598434.142 & & \\
\cline { 2 - 7 } & Total & 147818422.158 & 73 & & & \\
\hline
\end{tabular}


Table 5. Coefficients

\begin{tabular}{|c|c|c|c|c|c|c|c|c|c|c|c|c|}
\hline \multirow{2}{*}{ Model } & \multicolumn{2}{|c|}{$\begin{array}{c}\text { Unstandardized } \\
\text { Coefficients }\end{array}$} & \multirow{2}{*}{\begin{tabular}{|c|}
$\begin{array}{c}\text { Standardized } \\
\text { Coefficients }\end{array}$ \\
Beta \\
\end{tabular}} & \multirow[t]{2}{*}{ Q } & \multirow[t]{2}{*}{ Sig. } & \multicolumn{2}{|c|}{$\begin{array}{l}95.0 \% \text { Confidence } \\
\text { Interval for B }\end{array}$} & \multicolumn{3}{|c|}{ Correlations } & \multicolumn{2}{|c|}{$\begin{array}{l}\text { Collinearity } \\
\text { Statistics }\end{array}$} \\
\hline & B & Std. Error & & & & $\begin{array}{l}\text { Lower } \\
\text { Bound }\end{array}$ & $\begin{array}{l}\text { Upper } \\
\text { Bound }\end{array}$ & Zero-order & Partial & Part & Tolerance & VIF \\
\hline (Constant) & 1963.389 & 239.954 & & 8.182 & .000 & 1484.934 & 2441.843 & & & & & \\
\hline Case & -1.571 & .300 & -.344 & -5.227 & .000 & -2.170 & -.972 & -.126 & -.527 & -.333 & .936 & 1.068 \\
\hline LagTot.Freq & .006 & .000 & .862 & 13.117 & .000 & .005 & .007 & .776 & .841 & .835 & .936 & 1.068 \\
\hline
\end{tabular}

The due diligence of the regression model tested can be said to be feasible because of F-statistics of 88.004 with a significance of 0.000 (Table 4). The research model that uses real-time based consecutive time variables and lag $\mathrm{t}-1$, $\mathrm{t}-2$ empirically proves that the model remains fit [11]. The suitability of this good model shows that in times of crisis the role of black swan information about the impact of Covid-19 is significant in the model, in other words proven to play a role in influencing JCI. The level of conformity of the model also shows that Covid-19 affects capital markets [13]. Pandemics and restrictions cause supply shocks in employment, productivity, and markets. Going forward it will affect the company's performance, and those conditions are immediately responded to by exchanges with price declines and stock indices both in Germany, Japan, America and various European countries. Information about Covid-19 news influence the stock price and trading volatility, but there is an asymmetric impact on price and trading behavior. It related on macro-economy of each country $[14 ; 15]$. Furthermore, Table 5 presented the results of processing statistical data for the total test.

The model arranged can be said to be safe from the disruption of multi- collinearity with $\mathrm{VIF}<10$, and Tolerance $>0.10$. On the basis of using standardized, the Covid-19 regression coefficient is 0.344 and the Total Frequency lag is 0.862 . This suggests that the total influence of the composite remains dominant. The coefficient values inform that the research is based on standardized variables, where 2 different factors are performed standardized equalization. Standardized results show that the negative influence of Covid-19 outbreak is growing, and significant. The results also indicate that various news stories can be positive and negative in the capital markets and affect the market. This is also in line with signaling theory and prospect theory. The Covid-19 outbreak is a negative signal, causing the market to be negatively corrected. The speed of change in the Jakarta Stock-market Composite Index (JCI) can be explained by prospect theory that the investor often has to make decisions in situations where the information is less complete, and tends to seek a safe (risk averse). As a result, various news stories can be responded to quickly, although perhaps the market is inefficient. It also indicate the same thing, where the Covid-19 outbreak is rapidly affecting the stock market in various countries as in the European region [10]. The speed of Covid-19 information transmission because of the large information news flow in term of national or international scale. Rumors, or news can influence stock market activities so it impacted stock index [16].

\section{Discussion}

The news about Covid-19 prompted doubt and ambiguity among investors about the security of their investments. These doubts have an effect on the volatility of capital market performance reflected by the Jakarta Capital-market Index or Indonesia Stock Exchange (IDX) Index slump. Investor skepticism arises in the form of negative sentiment that the flow of selling interest in shares is greater than the buying interest, in addition to negative sentiment in the money market related to the capital market is the withdrawal of capital / foreign investment funds in IDX (capital outflow). Such negative sentiment affects stock prices and ultimately affects the performance of IDX in the form of a slump in JCI. This paper aims to analyze the effect of news about Covid-19 on market sentiment, the effect of Covid-19 rumors on market performance, how strongly Covid-19 rumors affect market performance, and how strong market sentiment was in the Covid-19 period on market performance.

The results are in line with previous research that tries to link the influence of Covid-19 on capital markets using daily data from January 23 to March 13, 2020, and found that news of the number of deaths from Covid-19 in each country of Germany, the UK, France co-ed with the FTSE, MIB, CAC40, DAX40 indexes [10]. Investors turn to gold investment, crypto currencies, and other derivative products. In fact, investors avoid risk as a result of the Covid-19 outbreak [10]. This condition indicates the movement or relationship between Covid-19 news and stock market performance on each country's exchanges. The impact of Covid-19 on the capital market can be said to be a form of continuous impact and stronger in a spiral (spillover impact). The use of distance restriction, lockdown, and various other policies will reduce transportation, production levels, sales and ultimately the performance of the company. As a result, exchange trading activities are also disrupted by restrictions on attendance and other activities. The impact of Covid-19 on the capital market can be categorized as a form of indirect influence and stronger than the result of the policy of rating on sector riel activities. This influence was examined using variance 
of internal restrictions, monetary policy, government spending, the number of Covid-19 cases [12]. Various fiscal and monetary policies are a stimulus of people's purchasing power to mobilize business and economic activities. The better the pace of the economy it is assumed that capital market activity and stock prices will be better. It was conducted by using variables of lockdown policies, government activity fund budgets, and variables depending on the share price and level of economic activity in leading stocks in various countries $[17 ; 18]$.

The results also in line with research examining the impact of Covid-19 on capital markets as conducted on Hong Kong and America capital markets in April 2020 [11]. The study is intended to look at the impact of Covid-19 on capital market returns in real time. The study was conducted in the form of predicted market return rates of the $\mathrm{t}$ period, based on the $\mathrm{t}-1$ and $\mathrm{t}-2$ periods on a daily basis. It was found that there was a good change in the decrease (increase) in multiples of $4 \%$ to $11 \%$ the next day. On the basis of this condition, it is expected that in the event of a rebound, the recovery will be faster. It was also found that stocks that suffered major declines/losses were stocks of capital-intensive companies that relied on leverage $[19,20]$. The losses are of greater due to the transmission of Covid-19 handling larger disbanding other types of companies. The findings also suggest that subsequent research on the decline in the company's stock market value is related to the rate of unemployment. Previous research on stock changes can be packaged into a cost-per-worker ratio versus a labor versus capital cost [11].

The study of Covid-19 was conducted in combination with several researchers with several methods namely: (i) catalyst of contagion; (ii) media attention; (iii) spillover effect at financial markets; (iv) macroeconomic fundamentals, suggesting that Covid-19 is a black-swan shock to the economy and financial and capital markets. The impact of Covid-19, considered a black swan, provides an overview of the financial conduct management of the broad research horizon on various things that can affect finances, both from data and new methods and aspects [9]. Covid-19 has a large impact on risk on economic and business as unpredictable (prevalent) event. The criterion is to appear surprisingly, influentially, and after its emergence it is necessary to look back [21].

\section{Conclusions}

The results of statistical analysis tell us that information about Covid-19 has a negative effect on JCI, as well as trading volume the previous day. This study empirically confirmed that the Covid-19 outbreak had an effect on Jakarta Composite Index (JCI). In addition to these variables, it was found that market conditions also affected JCI. The evidence can empirically prove that there is an effect of Covid-19 and weakening daily transactions on JCI. The research findings show that the JCI market uncertainty is in line with the VUCA and Prospect theory. Theoretically, the findings also presented the prospect theory as a critique of utility theory that assumes all can be ascertained, and rationality and tends to risk aversion, whereas the reality is not always the case, in certain circumstances people are forced to make decisions amid uncertainness, and cannot definitively calculate the probability (probability of events). Various natural decisions of high uncertain conditions will take the form of S-curve. At some point will increase then will decrease so in a row of ups and downs alternately. In other words, prospect theory can explain how this uncertain Covid-19 event will run on the behavior of capital market transactions and it will influence the market composite index.

In this case it occurs that uncertainty affects the behavior of investors' decision making. Investors' decision-making behavior is accumulated in market behavior, and is subsequently manifested in index changes in accordance with the efficient market hypothesis. The contribution of this research to the study of financial market behavior is that uncertainty and uncertainty faced by investors affect market behavior and changes as measured by the index. All of that can be explained by the theoretical prospect and the efficient market hypothesis.

For future research it is recommended that deepening is carried out with a more complete simultaneous model and more advanced analysis method than a simple linear regression model. Models that could be suggested as development or enhancements for future research (Appendix). The development of models that can be suggested in the form of simultaneous form research, and using more complete indicators to be known various specific impacts on the type of stock, the type of risk or the form of impact it has. 


\section{Appendix}

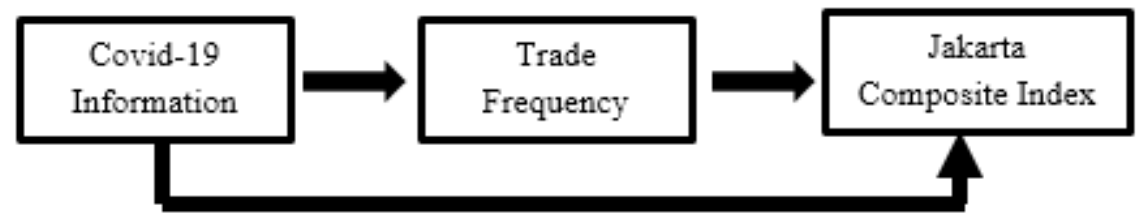

Figure 1. Proposed Improvements to the Model

\section{REFERENCE}

[1] Bennett N, Lemoine G J, "What a difference a word makes: Understanding threats to performance in a VUCA world," Business Horizons, vol. 57, no. 3, pp. 311-317, 2014.

[2] Kahneman, D., \& Tversky, A. "Prospect theory: An analysis of decision under risk". In Handbook of the fundamentals of financial decision making: Part I (pp. 99-127), 2013.

[3] Schindler, M. "Rumors in financial markets: Insights into behavioral finance" (Vol. 413). John Wiley \& Sons, 2007.

[4] Panda, B., \& Leepsa, N. M. "Agency theory: Review of theory and evidence on problems and perspectives". Indian Journal of Corporate Governance, 10(1), 74-95, 2017.

[5] Degutis, A., \& Novickyte, L. "The efficient market hypothesis: A critical review of literature and methodology". Ekonomika, 93, 7-23, 2014.

[6] Berk, C., \& Tutarli, B. "Dead or Alive: Modern Portfolio Theory Based on Financial Analysis". Universal Journal of Accounting and Finance, 8(4), 83-91, 2020. DOI: 10.13189/ujaf.2020.080401.

[7] Han, B., \& Hsu, J. "Prospect theory and its applications in finance". Imagine, 2004.

[8] Baum, C. F., Caglayan, M., \& Xu, B. "The impact of uncertainty on financial institutions" (No. 939). Boston College Department of Economics, 2018.

[9] Yarovaya, L., Brzeszczynski, J., Goodell, J. W., Lucey, B. M., \& Lau, C. K. "Rethinking Financial Contagion: Information Transmission Mechanism during the COVID-19 pandemic". Available at SSRN 3602973, 2020.

[10]Zeren, F., \& HIZARCI, A. "The impact of COVID-19 coronavirus on stock markets: evidence from selected countries". Muhasebe ve Finans Incelemeleri Dergisi, 3(1), 78-84, 2020.

[11] Alfaro, L., Chari, A., Greenland, A. N., \& Schott, P. K. "Aggregate and firm-level stock returns during pandemics, in real time" (No. w26950). National Bureau of Economic
Research, 2020.

[12] Ozili, P. K., \& Arun, T. "Spillover of COVID-19: impact on the Global Economy”. Available at SSRN 3562570, 2020.

[13] Liu, H., Manzoor, A., Wang, C., Zhang, L., \& Manzoor, Z. "The COVID-19 outbreak and affected countries stock markets response". International Journal of Environmental Research and Public Health, 17(8), 2800, 2020.

[14] Salisu, A. A., \& Vo, X. V. "Predicting stock returns in the presence of COVID-19 pandemic: The role of health news". International Review of Financial Analysis, 71, 101546, 2020.

[15] Nurwulandari A, Adnyana IM, Hasanudin H. Did Inter-Regional Trade Agreements Bring Mutual Benefits? An Empirical Scheme of Indonesian Commodity Exports in Asean-China Free Trade Area. International Journal of Financial Research, vol. 10, np. 6, pp. 241-249, 2019.

[16] Lee, K. Y. M., Jais, M., \& Chan, C. W. "Impact of covid-19: Evidence from malaysian stock market". International Journal of Business and Society, 21(2), 607-628, 2020.

[17] Misra, A. K. "Optimisation of return under risk constraint: An application on Indian banks". In 2011 International Conference on Financial Management and Economics, IPEDR (Vol. 11), 2011.

[18] Hasanudin H, Nurwulandari A, Adnyana IM, Loviana N. The Effect of Ownership and Financial Performance on Firm Value of Oil and Gas Mining Companies in Indonesia. International Journal of Energy Economics and Policy, vol. 10, no. 5, pp. 103.-109, 2020.

[19] Khoojine, A. S., \& Han, D. "Stock price network autoregressive model with application to stock market turbulence". The European Physical Journal B, 93(7), 1-15, 2020 .

[20] Adnyana M, Hasanudin H, Nurwulandari A. Empirical examination of intersectoral linkages between tourism and regional economy by using the social accounting matrix. International Journal of Economics and Business Administration, vol. 8, no. 1, pp. 425-432, 2020.

[21] Mishra, P. K. "COVID-19, Black Swan events and the future of disaster risk management in India". Progress in Disaster Science, 8, 100137, 2020. 